\title{
VISUAL IMPAIRMENT SECONDARY TO CONGENITAL GLAUCOMA IN CHILDREN: VISUAL RESPONSES, OPTICAL CORRECTION AND USE OF LOW VISION AIDS
}

\author{
Maria Aparecida Onuki Haddad, Marcos Wilson Sampaio, Ernst Werner \\ Oltrogge, Newton Kara-José, Alberto Jorge Betinjane
}

doi: 10.1590/S1807-59322009000800003

\begin{abstract}
Haddad MAO, Sampaio MW, Oltrogge EW, Kara-José N, Betinjane AJ. Visual impairment secondary to congenital glaucoma in children: visual responses, optical correction and use of low vision aids. Clinics. 2009;64(8):725-30.
\end{abstract}

INTRODUCTION: Congenital glaucoma is frequently associated with visual impairment due to optic nerve damage, corneal opacities, cataracts and amblyopia. Poor vision in childhood is related to global developmental problems, and referral to vision habilitation/rehabilitation services should be without delay to promote efficient management of the impaired vision.

OBJECTIVE: To analyze data concerning visual response, the use of optical correction and prescribed low vision aids in a population of children with congenital glaucoma.

METHOD: The authors analyzed data from 100 children with congenital glaucoma to assess best corrected visual acuity, prescribed optical correction and low vision aids.

RESULTS: Fifty-five percent of the sample were male, $43 \%$ female. The mean age was 6.3 years. Two percent presented normal visual acuity levels, $29 \%$ mild visual impairment, $28 \%$ moderate visual impairment, $15 \%$ severe visual impairment, $11 \%$ profound visual impairment, and 15\% near blindness. Sixty-eight percent received optical correction for refractive errors. Optical low vision aids were adopted for distance vision in 34\% of the patients and for near vision in 6\%. A manual monocular telescopic system with $2.8 \times$ magnification was the most frequently prescribed low vision aid for distance, and for near vision a +38 diopter illuminated stand magnifier was most frequently prescribed.

DISCUSSION AND CONCLUSION: Careful low vision assessment and the appropriate prescription of optical corrections and low vision aids are mandatory in children with congenital glaucoma, since this will assist their global development, improving efficiency in daily life activities and promoting social and educational inclusion.

KEYWORDS: Blindness; Glaucoma; Low Vision; Rehabilitation; Refractive Errors.

\section{INTRODUCTION}

Visual impairment in infancy results in a variety of developmental disorders in children. ${ }^{1}$ The etiology, degree of impairment, age of onset of the vision loss and other factors define the severity of the defects in the general development of the child. ${ }^{2}$

According to the $10^{\text {th }}$ revision of the International

Clínica Oftalmológica, Hospital das Clínicas da Faculdade de Medicina da Universidade de São Paulo - São Paulo/SP, Brazil

Email: maohaddad@uol.com.br

Tel: 55113069.7873

Received for publication on April 14, 2009

Accepted for publication on April 27, 2009
Statistical Classification of diseases and problems related to health, a person has low vision when their vision in the best corrected eye is within the 6/18 and 3/60 (categories 1 and 2 of visual loss), and they are blind when this value is below $3 / 60$ (categories 3,4 , and 5). ${ }^{3}$

The prevalence and causes of visual impairment in children (those below 16 years old, according to UNICEF) are variable across different regions of the world, and these statistics are related to social, economic and cultural factors. ${ }^{4,5}$ Foster estimate the number of blind children in the world to be around $1,500,000$, with $75 \%$ of this population in Asia and Africa.

In developed countries, genetic causes and congenital or prenatal birth problems are more prevalent, while nutritional 
factors, ocular infections, cataracts and congenital glaucoma are more often associated with the condition in developing countries. ${ }^{4-10}$

Congenital glaucoma occurs in one out of 10,000 live births. ${ }^{2}$ Visual loss secondary to congenital glaucoma may occur as a consequence of optical nerve damage, corneal opacities, cataracts and amblyopia. Even though the success rate of early treatment is approximately 70 to $80 \%$, only $35 \%$ of all patients will have visual acuity better than 20/50, and $2 \%$ to $15 \%$ will remain blind. ${ }^{2,11}$

Children who suffer from visual impairment as a result of congenital glaucoma should be referred to a low vision clinic, with the aim of improving their future general performance.

The objective of ophthalmic low vision therapy in children is to improve visual function through optical and non-optical aids, and/or electronic or computer devices. The aim is to modify (through magnification, filtration or sometimes minification) the retinal image, and to improve environmental conditions related to visual function. ${ }^{12}$

Magnification of the retinal image is the main resource in cases of low vision, and most treatment approaches involve one of four basic techniques: increasing the relative size of the object itself, increasing its relative size by reducing its relative distance, angular magnification (telescopes) and amplification by electronic projection. ${ }^{13}$

Optical devices provide various levels of magnification depending on their dioptric power, and must be used in accordance with certain criteria. The optimal performance of low vision aids requires an ophthalmologic low vision evaluation, measurement of the visual response, selection of the aid, and training for efficient use of the device and prescription..$^{13}$ According to Faye (1990), about $90 \%$ of patients with low vision can benefit from the use of optical devices. Video magnification and non-optical aids can be used alone or in conjunction with optical devices.

The objective of the present study was to evaluate data from a population of 100 children with congenital glaucoma that were assessed at the Congenital Glaucoma Unit and the Low Vision Unit of our facility. Our goal was to analyze their visual response with optical correction and use of low vision aids .

\section{METHOD}

The authors conducted a retrospective study of one hundred patients with bilateral congenital glaucoma who were assessed, submitted for surgery or clinical treatment at the Congenital Glaucoma Unit at our facility, and who ultimately presented with final intraocular pressure below $20 \mathrm{~mm} \mathrm{Hg}$. All the patients were also evaluated at the Low
Vision Unit at our facility. Patients with other associated disabilities or with no light perception were not included in this study.

The mean age of the studied patients was 6.3 years; the youngest was 1 month old and the oldest was 16 years old. Fifty-seven percent were male and $43 \%$ were female. Fortynine percent were of school age (6-16 years old).

At the Low Vision Unit, all the patients underwent the following exams, all of which were administered by the same ophthalmologists:

1 - A complete medical record of the patient was obtained, including a fundamental report regarding their previous treatment and information about their visual difficulties.

2 - Evaluation of visual function:

2.1 - Visual acuity: For children under 3 years of age, Teller acuity cards were utilized. For children above 3 years old but not yet literate, Lea symbol charts were employed. The Feinbloom chart was utilized for very low acuity children, and the Ferris-Bailey ETDRS table was used for literate children. Both near and distance visual acuity were evaluated.

2.2 - To assess color vision, the Ishihara test and the PV16 (Precision Vision Color) test were used.

2.3 - Evaluation of contrast sensibility: With collaborative children, two kinds of test were used: the Lea symbols low contrast test and the VCTS 6500 (Vistech).

2.4 - Visual field: The confrontation test was used in noncollaborative children, and the Goldmann perimeter was used in collaborative children. The Amsler test was used for the detection of central scotomas, and also to evaluate the pattern of vision of the studied patients. From this evaluation, the visual impairments of the children were characterized.

Children with a stable ocular condition were treated with refraction, prescription of optical corrections for refractive errors and low vision aids. Non-optical aids and electronic devices were also prescribed as needed.

This study evaluates the best corrected visual acuity in the better eye, the prescribed optical correction, and the visual acuity obtained with the recommended optical low vision aid(s). The best corrected visual acuity in the better eye was classified in degrees of visual impairment according to the Tenth Revision of International Statistical Classification of Diseases and Related Health Problems ${ }^{3}$ and by the International Council of Ophthalmology. ${ }^{14}$

The values of the prescribed optical corrections for refractive errors were expressed using spherical equivalents.

Low vision aids were used for children and adolescents of school age, including hand and stand magnifiers and special glasses for near vision, and telescopes of varying dioptric power and magnification for distance vision. 
The University Ethics Committee at our facility approved the study protocol.

\section{RESULTS}

In terms of visual acuity, $2 \%$ of the patients presented normal vision; $29 \%$ presented mild vision loss; $28 \%$ presented moderately low vision; $15 \%$ presented severe low vision; $11 \%$ presented profound low vision, and $15 \%$ presented near blindness (Table 1).

Table 1 - Distribution of children with congenital glaucoma according to the best corrected visual acuity in the better eye

\begin{tabular}{|c|c|c|c|}
\hline Degree of visual impairment & Visual acuity & $\mathrm{N}$ & $\%$ \\
\hline Normal vision* & $20 / 12.5<\mathrm{AV} \leq 20 / 25$ & 2 & 2 \\
\hline Near normal vision* & $20 / 25<\mathrm{AV} \leq 20 / 63$ & 29 & 29 \\
\hline $\begin{array}{l}\text { Moderate visual impairment* } \\
\left(1^{* *}\right)\end{array}$ & $20 / 63<\mathrm{AV} \leq 20 / 200$ & 28 & 28 \\
\hline $\begin{array}{l}\text { Severe visual impairment* } \\
\left(2^{* *}\right)\end{array}$ & $20 / 200<\mathrm{AV} \leq 20 / 400$ & 15 & 15 \\
\hline $\begin{array}{l}\text { Profound visual impairment* } \\
\left(3^{* *}\right)\end{array}$ & $20 / 400<\mathrm{AV} \leq 20 / 1200$ & 11 & 15 \\
\hline $\begin{array}{l}\text { Near blindness* } \\
(4 * *)\end{array}$ & $\begin{array}{l}20 / 1200<\mathrm{AV} \leq 20 / 2000 \\
\text { Hand motion perception } \\
\text { Light perception }\end{array}$ & $\begin{array}{l}5 \\
5 \\
5\end{array}$ & $\begin{array}{l}5 \\
5 \\
5\end{array}$ \\
\hline Total & & 100 & 100 \\
\hline
\end{tabular}

Optical correction was recommended for $68(68 \%)$ of the patients, with 57 corrected in both eyes, and 11 corrected in only one eye (total: 125 eyes with optical correction). Regarding the optical prescriptions, $80 \%$ were corrections for myopia and $20 \%$ were for hyperopia and astigmatism.

Spherical equivalents between -4.00 and -8.00 diopters constituted $22.4 \%$ of the optical prescriptions; $28 \%$ were between -4.00 and 0 diopters, and $17.6 \%$ were between 8.00 and -12.00 diopters (Table 2).

Optical devices for distance were prescribed for 34 ( $34 \%$ ) of the patients. All of the optical aids for distance were telescopic manual systems for one eye only, and the magnifications used were $2.8 \times(32.4 \%), 6 \times 20(23.5 \%)$ and $4.2 \times 12(20.6 \%)$ (Table 3).

Optical aids for near vision were necessary for $6(6 \%)$ of the patients, and the most commonly prescribed were illuminated stand magnifiers of +38 aspheric diopters (33.4\%), 2X reading bar stand magnifiers $(33.4 \%)$, illuminated stand magnifiers of +28 aspheric diopters $(16.6 \%)$, and high plus lenses of +24 aspheric diopters assembled in spectacles for monocular use (16.6\%) (Table 4).
Table 2 - Distribution of the spherical equivalent dioptric values of the optical corrections prescribed to children with congenital glaucoma

\begin{tabular}{lcc}
\hline $\begin{array}{l}\text { Optical correction prescribed in spheri- } \\
\text { cal equivalents (E) }\end{array}$ & N (eyes) & $\%$ \\
\hline$-24<\mathrm{E} \leq-20$ & 1 & 0.8 \\
$-20<\mathrm{E} \leq-16$ & 7 & 5.6 \\
$-16<\mathrm{E} \leq-12$ & 6 & 4.8 \\
$-12<\mathrm{E} \leq-8$ & 22 & 17.6 \\
$-8<\mathrm{E} \leq-4$ & 28 & 22.4 \\
$-4<\mathrm{E}<0$ & 36 & 28.8 \\
$0<\mathrm{E} \leq+4$ & 16 & 12.8 \\
$+4<\mathrm{E} \leq+8$ & 4 & 3.2 \\
$+8<\mathrm{E} \leq+12$ & 2 & 1.6 \\
$+12<\mathrm{E} \leq+16$ & 2 & 1.6 \\
$+16<\mathrm{E} \leq+20$ & 1 & 1.6 \\
\hline Total & 125 & 100 \\
\hline
\end{tabular}

Table 3 - Distribution of the optical aids for distance prescribed to children with congenital glaucoma

\begin{tabular}{lcc}
\hline $\begin{array}{l}\text { Optical aid for distance (telescopes, } \\
\text { manual and monocular ) }\end{array}$ & $\mathrm{N}$ & $\%$ \\
\hline $2 \times 26 \mathrm{~mm}$ & 3 & 8.8 \\
$2.5 \times 26 \mathrm{~mm}$ & 2 & 5.9 \\
$2.8 \times 26 \mathrm{~mm}$ & 11 & 32.4 \\
$4.2 \times 12 \mathrm{~mm}$ & 7 & 20.6 \\
$6 \times 17 \mathrm{~mm}$ & 8 & 23.5 \\
$8 \times 21 \mathrm{~mm}$ & 3 & 8.8 \\
\hline Total & 34 & 100 \\
\hline
\end{tabular}

Table 4 - Distribution of the optical aids for near vision prescribed to children with congenital glaucoma

\begin{tabular}{llc}
\hline NEAR OPTICAL AID PRESCRIBED & $\mathrm{N}$ & $\%$ \\
\hline +24 diopter aspherical lens (monocular glasses) & 1 & 16.6 \\
+28 diopter illuminated stand magnifier & 1 & 16.6 \\
+38 diopter illuminated stand magnifier & 2 & 33.4 \\
2X reading bar & 2 & 33.4 \\
\hline Total & 6 & 100 \\
\hline
\end{tabular}

Of the school-aged children, $69.3 \%$ had optical aids prescribed for distance (telescopes) and $12.2 \%$ had optical aids prescribed for near vision.

The visual acuity values of the 34 children for whom optical aids were prescribed are listed in Table 5 The distribution of best corrected visual acuity in the better eye 
Table 5 - Distribution of children with low vision secondary to congenital glaucoma according to values of corrected visual acuity with and without optical aids for distance (telescopes)

\begin{tabular}{lccc}
\hline Degree of visual impairment & Visual acuity & Without optical aid (N \%) & With optical aid (N \%) \\
\hline Normal vision* & $20 / 12.5<\mathrm{AV} \leq 20 / 25$ & -- & $11(32.4)$ \\
Mild vision impairment* & $20 / 25<\mathrm{AV} \leq 20 / 63$ & $4(11.8)$ & $14(41.2)$ \\
Moderate visual impairment* $(1 * *)$ & $20 / 63<\mathrm{AV} \leq 20 / 200$ & $20(58.8)$ & $7(20.6)$ \\
Severe visual impairment* $(2 * *)$ & $20 / 200<\mathrm{AV} \leq 20 / 400$ & $4(11.8)$ & $2(5.8)$ \\
Profound visual impairment* $(3 * *)$ & $20 / 400<\mathrm{AV} \leq 20 / 1200$ & $6(17.6)$ & -- \\
\hline Total & & 34100 & 34100 \\
\hline
\end{tabular}

* International Council of Ophthalmology, 2002. ${ }^{11}$

** WHO International Statistical Classification of Diseases and Related Health Problems 10th Revision. ${ }^{3}$

of this group was as follows: near normal vision, $11.8 \%$; moderate low vision, $58.8 \%$; severe low vision, $11.8 \%$ and profound low vision, $17.6 \%$.

With the use of optical aids for distance (telescopes), we observed the following distribution: $32.4 \%$ with normal visual acuity values, $41.2 \%$ with mild vision loss, $20.6 \%$ with moderate low vision and $5.8 \%$ with severe low vision.

\section{DISCUSSION AND CONCLUSIONS}

The visual outcome of a child with congenital glaucoma is closely related to the age at which the diagnosis is made and the subsequent treatment trajectory. A familial history of glaucoma should be taken into account as early as possible. ${ }^{15}$ Assessment of visual function in children with congenital glaucoma must be initiated at the time of diagnosis, so that these data may be used as a reference during follow-up. In the present study, $28 \%$ of the patients presented with moderate low vision; $29 \%$ presented with near normal acuity values and $2 \%$ exhibited normal acuity values.

Visual loss in childhood glaucoma is multifactorial. Corneal opacities, uncorrected refractive error, anisometropic or strabismic amblyopia and optic nerve lesions can all contribute to poor vision in these children. Corneal edema during the first three months of life leads to vision worse than $20 / 200$ in approximately $50 \%$ of these children. ${ }^{16,17}$ Corneal edema results from elevated intraocular pressure and is often the presenting sign in infants younger than 3 months. Microcystic edema initially involves the corneal epithelium but later extends to the stroma, often accompanied by one or more breaks in Descemet membrane (Haab striae). Intraocular pressure reduction resolves corneal edema but a scar will remain permanently at the Haab striae site. $^{11}$

Optical correction was prescribed in $68 \%$ of the patients, and in the majority of these individuals the correction was for myopia and/or myopic astigmatism $(80 \%)$. The correlation between myopia and glaucoma is due to the increase in the axial diameter of the eye as a consequence of the high intraocular pressure. ${ }^{16-20}$ Astigmatisms are usually related to corneal irregularities (unequal expansion of the anterior segment, corneal scarring and opacification or dislocation of the lens). ${ }^{16,17}$

Amblyopia may occur when refractive errors were not corrected earlier, especially in unilateral cases. According to Fonda (1986), about $15 \%$ of patients that attend a low vision clinic require only optical correction of their refractive errors. ${ }^{17,19}$

In the present study, $49 \%$ of the patients were between 6 and 16 years old (school age), and $69.4 \%$ had been prescribed optical devices.

Telescopic systems (angular magnification), both monocular and manual, were employed to improve visual resolution at a distance, primarily to assist with reading texts on a blackboard. Telescopes with a magnification of $2.8 \mathrm{X}$ were more commonly prescribed $(32.4 \%)$. Telescopic systems with low magnification such as these are frequently used by children of pre-school and school age due to their ease of manipulation and their large field of vision. They are beneficial in cases of retraction of the visual field, reduction of image illumination, parallax movements and also in mitigating the disturbance of space perception that occurs with all optical devices. ${ }^{21}$ The daily activities of a person can usually be adequately performed with a corrected visual acuity of around 20/40. ${ }^{21}$ The use of telescopic systems in visually impaired school children should be promoted, even for school activities, and children that need them should receive them as early as possible. In this way, we can increase their visual ability, avoid losing precious development time and help them understand the benefits of their use. ${ }^{12,22}$

Patients with visual acuity better than 20/400 will have a greater chance of success with the use of optical aids. ${ }^{13,23,24}$

In the present study, we observed that of the 34 children and adolescents who were prescribed optical devices, 28 (45\%) presented with visual acuity of better than 20/400. 
Optical aids for near vision were prescribed less often (6\% of all patients). A larger range of accommodation in the child allows for an enlargement of the retinal image by decreasing the distance between the eye and the object under inspection while keeping it in focus. This makes the use of near vision optical aids less necessary. Many children with optical correction for myopia were simply advised to take off their glasses and move closer to the text. This strategy permits an enlargement of the image of the text by decreasing the relative distance, and it increases visual comfort through the use of less accommodation.

According to Lindsted (1986), some children with low visual acuity present with inadequately developed visual accommodation as a consequence of a lack of positive input from the well-focused images that children with normal vision regularly perceive. ${ }^{21}$ This alone could justify the use of additional plus lenses for near vision.

Ophthalmologists should collaborate with the family and schoolteachers in order to explain the disease and offer expert advice regarding the use of optical correction along with the prescribed optical and/or non-optical devices. This may help fully integrate children with low vision into school settings and social environments. ${ }^{12,21}$

The importance of the school staff in observing the visual difficulties of the child and their role in referring those in need to specialized medical services cannot be overemphasized.

In children with congenital glaucoma, the first priority is clinically controlling the disease. However, it is also necessary to prescribe optical correction for refractive errors and low vision aids as needed, and to schedule a program of future evaluations and careful assessments of their visual function.

In conclusion, children with low vision due to congenital glaucoma can clearly benefit by having their refractive errors corrected and by using optical low vision aids. This study suggests that it is important to stimulate the efficient use of vision in infancy, as this promotes the global development of these children, improves their activity profiles, and contributes to the process of school and social integration.

\section{REFERENCES}

1. Hyvarinen L. Effect on impaired vision on general development. In: Vision testing manual. Villa Park: Precision Vision; 1995. p 1-7.

2. Teplin SU. Visual impairment in infants and young children. Inf. Young children. 1995;8:18-51.

3. Organização Mundial da Saúde. Classificação Estatística Internacional de Doenças e Problemas Relacionados à Saúde. Décima Revisão. São Paulo: Edusp; 1993. p.457.

4. World Health Organization - Programme for the Prevention of Blindness - Management of low vision in children - Report of a WHO Consultation. Bangkok, 1992. 48p. (WHO/PBL/93.27).

5. Foster A, Gilbert C. Epidemiology of childhood blindness. Eye. 1992;6:173-6.

6. Haddad MAO, Sei M, Braga AP, Sampaio MW, Kara-José N. Causes of visual impairment in childhood and adolescence: a retrospective study of 1917 cases. In:Stuen C, Arditi A, Horowitz A, Lang MA, Rosenthal B, Seidman K, editors. Vision Rehabilitation. Assessment, intervention and outcomes. New York: Swets \& Zeitlinger Publishers; 2000. p 371-5.

7. Kara-José N, Carvalho KMM, Pereira VL, Venturini NHB, Gasparetto MEFR, Gushiken MT. Estudo retrospectivo dos primeiros 140 casos atendidos na Clínica de Visão Subnormal do Hospital de Clínicas da Unicamp. Arq. Bras. Oftalmol. 1988;51:65.

8. Carvalho KM, Minguini N, Moreira Filho D, Kara-José N. Characteristics of a pediatric low-vision population. J.Pediatr.Ophthalmol.Strabismus. 1996:35:162-5.
9. Haddad MAO, Sei M, Sampaio MW, Kara-José N. Causes of visual impairment in children: Study of 3210 cases. J. Pediatr. Ophthalmol. Strabismus. 2007;44:232-40.

10. Haddad MAO, Lobato FJC, Sampaio MWS, Kara-José N. Pediatric and adolescent population with visual impairment: study of 385 cases. Clinics. 2006;61:239-46.

11. Buckley EG. Primary congenital open angle glaucoma. In: Epstein DL, Allingham RR, Schuman JS, eds. Chandler and Grant`s Glaucoma. $4^{\text {th }}$ ed. Baltimore: Williams \& Wilkins.1997:958-608.

12. Haddad MAO, Sampaio MW, Kara-José N. Baixa visão na infância. Manual básico para oftalmologistas. São Paulo, Laramara; 2001.

13. Sampaio MW, Haddad MAO, Kara-José N. Auxílios para baixa visão. São Paulo, Laramara; 2001.

14. Colenbrander A . Visual Standards. ICO report. Sydney, April, 2002.

15. Vegini F, Figueiroa Filho N, Lenci RF, Garcia Neto D, Susanna Junior R. Prevalence of open angle glaucoma in accompanying first degree relatives of patients with glaucoma. Clinics. 2008;63:329-32.

16. Catalano RA, Nelson LB. Pediatric Ophthalmology. Norwalk: Appleton \& Lange; 1994.

17. Simon JW, Buckely EG, Drack AV, Hutchinson AK, Plager AS, Raab EL, et al. Pediatric Ophthalmology and Strabismus. San Francisco: American Academy of Ophthalmology.2003;253-63. 
18. Betinjane AJ, Carvalho AV. Refração e biometria no glaucoma congênito. Arq. Bras. Oftalmol. 1983;46:96-9.

19. Carani JCE, Betinjane AJ, Carvalho AC. Método para avaliação da refração ocular no glaucoma congênito. Arq. Bras. Oftalmol. $1984 ; 57: 137$

20. Fonda G. Most usefal visual aids for the partially sighted. In: Woo G. editor. Low Vision . Principles and Applications.Waterloo: SpringerVerlag. 1986;p232-42.

21. Lopes JMV. Apuntes Sobre Rehabilitocion Visual . Madrid: Organizacion Nacional de Ciegos Españoles. 1994.
22. Haddad MAO, Braga AP, Sei M, Sampaio MW, Kara-José N. Low cost telescopic system: its effectiveness in cases of macular retinochoroiditis due to congenital toxoplasmosis. In:Stuen C, Arditi A, Horowitz A, Lang MA, Rosenthal B, Seidman K, editors. Vision Rehabilitation. Assessment, intervention and outcomes. New York: Swets \& Zeitlinger Publishers. 2000;p.195-9.

23. Faye EE Padula WV, Gurland JE, Grennberg ML, Hood CM. The low vision child. In: Faye EE - Clinical Low Vision. 2ed. Boston: Little, Brown and Company;1984. p.437-75.

24. Lindsted E. Accomodation in the visually Impaired Child. In: Woo G. editor. Low Vision. Principles and Applications. Waterloo: SpringerVerlag. 1986;425-35. 